\title{
Triptolide as a novel agent in pancreatic cancer: the validation using patient derived pancreatic tumor cell line
}

\author{
Seung Tae Kim ${ }^{\dagger}$ Sun Young Kim ${ }^{\dagger}$, Jeeyun Lee, Kyung Kim, Se Hoon Park, Young Suk Park, Ho Yeong Lim, \\ Won Ki Kang and Joon Oh Park
}

\begin{abstract}
Background: Triptolide induces apoptosis and DNA damage followed by inhibition of DNA repair associated gene expression. However, there is the limited data for biomarker to predict the benefit to triptolide in various cancers including pancreatic cancer.

Methods: We investigated the anti tumor efficacy of triptolide in various pancreatic cancer cell lines (Capan-1, Capan2, SNU-213, SNU-410, HPAFII, and Hs766T) and patient derived cells (PDCs) from metastatic pancreatic cancer patients.

Results: In vitro cell viability assay for triptolide in 6 PC cell lines, the IC 50 was $0.01 \mathrm{uM}, 0.02 \mathrm{uM}, 0.0096$ uM for triptolide in Capan-1, Capan-2 and SNU-213. However, the growth of tumor cells was not significantly reduced by triptolide in Hs766T, SNU-410 and HPAFII. The distinct difference of gene expression was also observed between Capan-1, Capan-2 and SNU-213 and Hs766T, SNU-410 and HPAFII. In analysis of pathway using gene expression profiles, the integrin mediated RAS signaling pathway was associated with the sensitivity of the triptolide in PC cell lines. Immunoblot assay showed that Chk2 phosphorylation after triptolide was distinctively observed in SNU-213 sensitive to triptolide but, not in SNU-410 insensitive to triptolide. This finding in immunoblot assay was also reproduced in PDCs originated from pancreatic cancer patients.

Conclusions: Our findings might be helpful to completely capture the subset of patients who may benefit to tripolide (minnelide). More robust biomarkers such as KRAS mutation and Chk2 phosphorylation and careful clinical trial design using triptolide (minnelide) are warranted.
\end{abstract}

Keywords: Patient derived cells (PDCs), Triptolide, Chk2

\section{Introduction}

Pancreatic cancer is an aggressive and highly fatal malignancy affecting a large number of individual worldwide, and survival 5 years after diagnosis is less than $5 \%$ with only $15 \%$ for the patients eligible for surgical resection at presentation [1-3]. Various factors cause this poor prognosis, including aggressive tumor biology and drug resistance to pancreatic tumor cells [4-6]. Although some chemotherapeutic agents such as gemcitabine, erlotinib, abraxene, oxaliplatin and irinotecan have taken to

\footnotetext{
* Correspondence: oncopark@skku.edu

'Seung Tae Kim and Sun Young Kim contributed equally to this work. Division of Hematology-Oncology, Department of Medicine, Samsung Medical Center, Sungkyunkwan University School of Medicine, 81 Irwon-ro, Gangnam-gu, Seoul 06351, South Korea
}

survival advantage, there is still urgent needs to discover and develop more effective treatment-options against pancreatic cancer $[7,8]$.

KRAS mutation has been known as being present in 70 95\% of pancreatic cancers [9]. KRAS mutation has been known as crucial marker for growth and maintenance of pancreatic cancers and targeting the KRAS is inevitable component for realizing precision medicine to pancreatic cancers. Tripolide is a diterpenoid triepoxide derived from the herb Tripterygium wilfordii, which has been utilized as a natural agent [10]. Triptolide has shown great promise in preclinical studies using immotalized pancreatic cancer lines in immunocompromised mouse model [11]. Triptolide induces apoptosis and DNA damage followed by inhibition of DNA repair

(c) The Author(s). 2018 Open Access This article is distributed under the terms of the Creative Commons Attribution 4.0 International License (http://creativecommons.org/licenses/by/4.0/), which permits unrestricted use, distribution, and reproduction in any medium, provided you give appropriate credit to the original author(s) and the source, provide a link to the Creative Commons license, and indicate if changes were made. The Creative Commons Public Domain Dedication waiver (http://creativecommons.org/publicdomain/zero/1.0/) applies to the data made available in this article, unless otherwise stated. 
associated gene expression [12-14]. However, there is the limited data for biomarker to predict the benefit to triptolide in various cancers including pancreatic cancer.

Herein, we investigated the anti tumor efficacy of triptolide in various pancreatic cancer cell line. Additionally, we also intended to analyze the difference of signal pathway based on gene expression and conduct the immunoblot assay according to the status of sensitivity to triptolide. Further, anti-tumor effect of triptolide was verified through PDCs from metastatic pancreatic cancer patients with and without KRAS mutation.

\section{Material and methods Patient}

This investigation was conducted in accordance with the ethical standards of the Declaration of Helsinki and national and international guidelines, and was approved by the Institutional Review Board at Samsung Medical Center. Between October 2013 and Jan 2016, patients with gastrointestinal cancer, rare cancer, and lung cancer prospectively enrolled in the SMC Oncology Biomarker study (Ref. No. 2011-07-089). The PDC culture protocol was performed for eligible patients. All of the primary tumors from the patients who provided written informed consent were genomically sequenced. In parallel, PDC establishment was attempted for all sequenced tumors.

\section{Cell lines and patient-derived cell culture}

Triptolide was treated on six pancreatic cancer cell lines in vitro. Lines Hs766T and HPAFII were obtained from ATCC (American Type Culture Collection, Rockville, MD, USA). Lines SNU-410, Capan-1, Capan-2, and SNU-213 were obtained from KCLB (Korean Cell Line Bank, Seoul, Korea). Cells were cultured in RPMI, DMEM, or MEM media according to the manufacturer's methods, supplemented with $10 \%$ of fetal bovine serum and $1 \%$ of antibiotic-antimycotic solution (Gibco, Carlsbad, CA, USA).

For culture of patient derived pancreatic cancer cells, malignant effusions or tumor tissue biopsy from patients with metastatic cancer was collected from patients who had provided informed consent. Collected effusions (1$5 \mathrm{~L})$ were divided into $50 \mathrm{~mL}$ tubes, centrifuged at $1500 \mathrm{rpm}$ for $10 \mathrm{~min}$, and washed twice with PBS. Cell pellets were resuspended in culture medium and plated into $75 \mathrm{~cm} 2$ culture flasks. Collected tissue was minced and dissociated with enzymatic method. The cells were grown in RPMI 1640 supplemented with 10\% fetal bovine serum and $1 \%$ antibiotic-anti-mycotic solution, $0.5 \mu \mathrm{g} / \mathrm{ml}$ of hydrocortisone (Sigma Aldrich, St. Louis, MO, USA), $5 \mu \mathrm{g} / \mathrm{ml}$ of insulin (PeproTech, Rocky Hill, NJ, USA), $5 \mathrm{ng}$ of EGF and $2.5 \mathrm{ng}$ of FGF (PeproTech). The medium was changed every 3 days, and cells were maintained at
$37{ }^{\circ} \mathrm{C}$ in a humidified $5 \% \mathrm{CO}_{2}$ incubator. PDCs were detached using TrypLE Express (Gibco BRL) to subculture when the cells reached $80-90 \%$ confluence.

\section{Cell treatment and viability assay}

To observe the effect of triptolide, cells were seeded on $1 \sim 2 \times 10^{6}$ cells/10 mm dishes or 5000 cells/ well/ 96-well plate for analysis of immunoblotting and cell proliferation inhibition assay. Cells were treated for 3 5 days with various doses of drugs as indicated in the Fig. 1. Cell proliferation inhibition was determined via Cell Titer Glo (Promega, Madison, WI, USA) according to the manufacturer's protocol.

\section{Affymetrix microarray analysis}

The array data for GSE36133, were downloaded from the Gene Expression Omnibus (GEO; http://www.ncbi.nlm.nih.gov/geo/) database, as reported by CCLE [15]. A total of 917 samples were used in the development of the Affymetrix microarray data. The expression profiles analyzed in this work were derived from six samples, including three samples of triptolide sensitive cell line and three samples of three samples of triptolide resistant cell line. The raw CEL data and annotation files were downloaded based on the GPL15308 platform for further analysis.

\section{Data processing and DEG analysis}

The raw expression data were preprocessed using the gcrma algorithm with application of the EMA package in the $\mathrm{R}$ statistical software (version 3.1.2; Bell Labs, Murray Hill, NJ, USA) [16]. When multiple probes corresponded to the same gene, the mean value was calculated as the expression value of that gene.

The DEGs between triptolide sensitive cell line and resistant cell line were analyzed using the runWilcox. |log of fold change| $>1$ were considered to be the cut-off values for DEGs screening. The 529 DEGs were ranked based on their Wilcoxon $P$-values and the markers with the lowest $P$-values were selected.

\section{Gene ontology (GO) and pathway enrichment analysis}

The gene sets enriched in specific subtypes were further applied to ClueGO tool in Cytoscape to visualize significant gene ontology hierarchy and functional interaction maps between DEGs $[17,18]$.

The DEGs were classified into three GO categories, including molecular function (MF), biological process (BP) and cellular component $(\mathrm{CC}) . \quad P<0.05$ was set as the threshold value.

\section{Immunoblot analysis}

Total proteins from cells were isolated by cOmplete Lysis-M (Roche) containing a protease inhibitor cocktail (Roche, Mannheim, Germany) and phosphatase inhibitor 


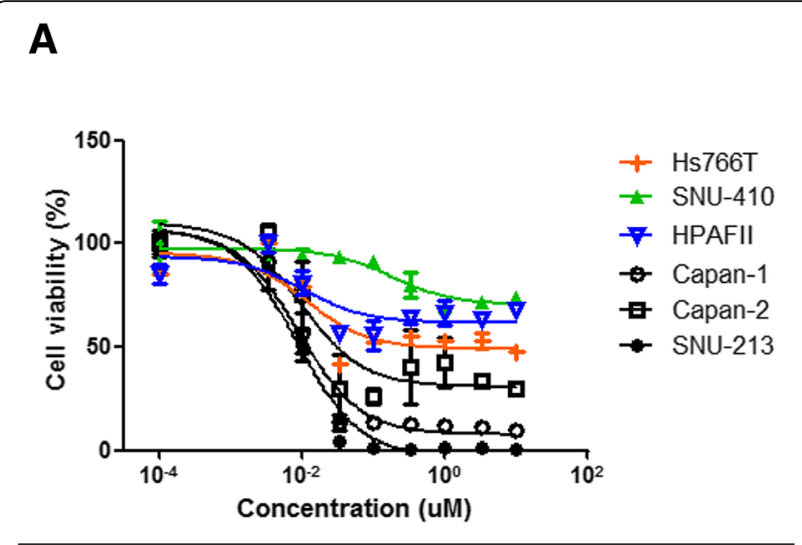

B
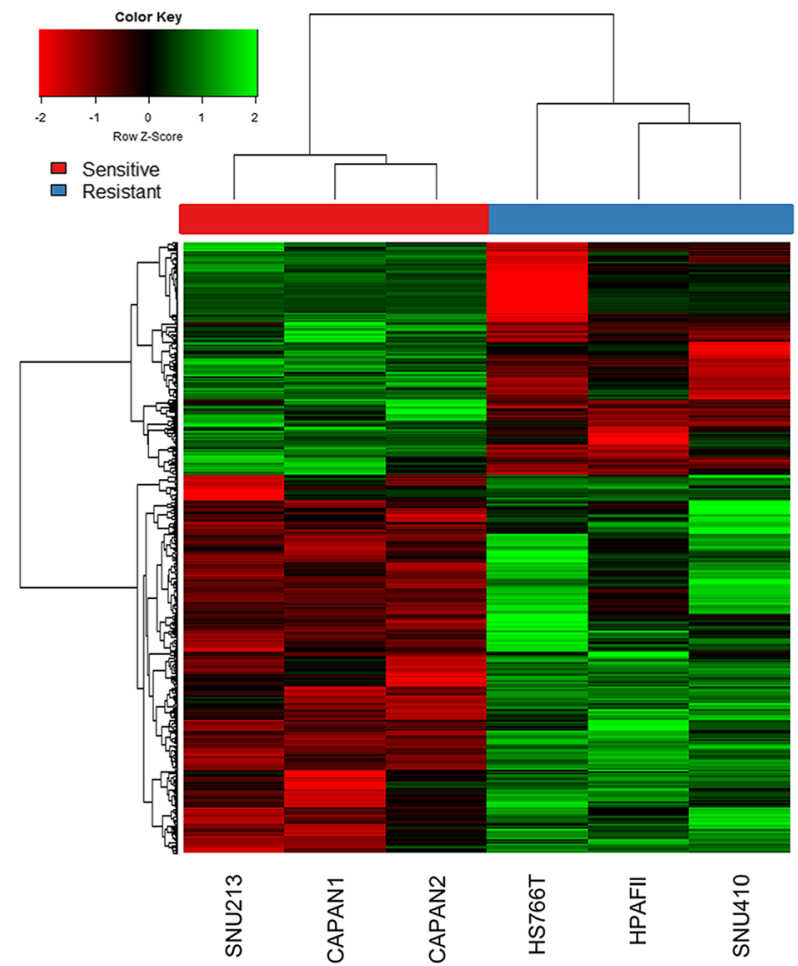

Fig. 1 a Cell proliferation inhibition curve of triptolide on pancreatic cell lines. b A heat map generated using the 529 DEGs between triptolide sensitive cell line and resistant cell line. A heat map was constructed using the genes based on Pearson correlation distance and average linkage method

cocktail (Roche), and protein concentrations were determined according to Bradford procedure using a Quick Start Bradford Protein Assay (Bio-Rad, Hercules, CA, USA). Thirty micrograms of proteins were subjected to $10 \%$ SDS-polyacrylamide gel electrophoresis, and electro-transferred onto nitrocellulose membranes. The membranes were blocked with $5 \%$ nonfat dry milk in Tris-buffered saline containing $0.1 \% v / \mathrm{v}$ Tween 20, and probed overnight at $4{ }^{\circ} \mathrm{C}$ with a Specific antibodies: phospho-ATM (Ser1981), ATM (D2E2), phospho-ATR (Ser428), ATR (E1S3S), phospho-Chk1 (Ser345), Chk1 (2G1D5), phospho-Chk2 (Thr68), Chk2 (1C12), Cyclin A2 (BF683), Cyclin D1 (92G2), and Cyclin E2 from Cell Signaling Technology (Beverly, MA, USA), Integrin beta1 from abcam (Cambridge, UK) and beta actin from Sigma Aldrich. Horseradish peroxidase-conjugated anti-rabbit or mouse IgG (Vector, Burlingame, CA, USA) were used as a secondary antibody, and signals were detected by chemiluminescence using ECL Western Blotting Substrate (Thermo Scientific, Rockford, IL, USA), and visualized by using LAS-4000 (Fujifilm, Tokyo, Japan).

\section{Droplet digital PCR test of KRAS mutations}

KRAS G12 V mutation levels of patient derived cells were measured using a ddPCR system (Bio-Rad Laboratories, Hercules, CA, USA). Briefly, sequence of primers and probes for detection were provided from Taq man (assay ID: KRAS_520). Total 20 ul of PCR mixture was loaded into a 24-well consumable droplet generation cartridge. The water-in-oil emulsions were transferred to a 96-well PCR plate and subjected to amplification cycles. (Cycling protocol: $95{ }^{\circ} \mathrm{C}$ for $10 \mathrm{~min}, 40$ cycles of $94{ }^{\circ} \mathrm{C}$ for $30 \mathrm{~s}$ and $60{ }^{\circ} \mathrm{C}$ for $1 \mathrm{~min}$, and a final step at $98{ }^{\circ} \mathrm{C}$ for $10 \mathrm{~min}$ ). Then plates were loaded into the com-mercially obtained QX100 droplet reader (Bio-Rad). Concentrations of targets in the samples were analyzed by using QuantaSoft software as manufacturer's instruction.

\section{Statistical method}

For cell viability curves, results are expressed as the means. Paired one way ANOVA tests were used to calculate the $P$ values. Statistical significance was assessed using one way ANOVA tests and described in the figure.

\section{Results}

Anti-tumor effect of triptolide in various pancreatic cell lines

In vitro cell viability assay for triptolide in $6 \mathrm{PC}$ cell lines (Capan-1, Capan-2, SNU-213, SNU-410, HPAFII, and Hs766T), the $\mathrm{IC}_{50}$ was $0.01 \mathrm{uM}, 0.02 \mathrm{uM}, 0.0096 \mathrm{uM}$ for triptolide in Capan-1, Capan-2 and SNU-213. However, 
the growth of tumor cells was not significantly reduced by triptolide in Hs766T, SNU-410 and HPAFII (Fig. 1a).

To investigate distinction of gene expression in the sensitivity of triptolide, the gene expression analysis was performed in 6 PC cell lines (Capan-1, Capan-2, SNU-213, Hs766T, SNU-410 and HPAFII). The mRNA microarray data were constructed based on Pearson correlation distance and average linkage method. Five hundred twenty-nine genes were differently distributed on between PC cell lines with and without the sensitivity to triptolide (Fig. 1b).

To understand the biochemical, cellular, or biological functions in the large list of DEGs, we further analyzed a comprehensive functional gene ontology (GO) using KEGG and GO_BP tool. In analysis of pathway using gene expression profiling, the integrin mediated RAS signal pathway was associated with the sensitivity of the triptolide among PC cell lines (Fig. 2 and Additional file 1: Table S1).

\section{Cell viability assay with triptolide and immunoblot assay} using pancreatic cancer (PC) patients derived cells (PDCs) PDCs were established from metastatic lesions of KRAS G12 V mutant pancreatic cancer patient (PDC\#1) and KRAS wild type patient (PDC\#2), respectively, as described in the Material and methods section. We also confirmed the KRAS G12 V mutation in PDCs by ddPCR. First, we conducted the cell viability assay with triptolide using above two PDCs. Cell viability assays showed that triptolide suppressed the cell viability of only PDCs with KRAS G12 V mutation. PDCs with
KRAS wild type was not inhibited by triptolide (Fig. 3a). We also analyzed the regulation of DNA damaged signals such as ATM/ATR/Chk1/Chk2 upon exposure to triptolide by immunoblot assay using PDCs. After triptolide, Chk2 phosphorylation was distinctively observed in PDCs sensitive to triptolide but, not PDCs insensitive to triptolide (Fig. 3b). This finding was consistent to that of immunoblot assay using cell lines (Fig. 4).

\section{Discussion}

The treatment for metastatic pancreatic cancer need to be advanced. Rapid advances in molecular technologies together with improved algorithms for detecting specific molecular aberrations have made it feasible to perform biomarker-matched treatment $[19,20]$. However, the role of molecular targeted therapy has not been established in pancreatic cancer. Although about $90 \%$ of pancreatic cancers harbor activated driver oncogenic KRAS, effective molecular targeted agent against KRAS mutation has not been developed until now [9]. Herein, we demonstrated that triptolide is a potent inhibitor in pancreatic cell lines and KRAS mutant PDCs. Consistent with the inhibition of cellular growth, we also observed the phosphorylation of Chk2 in cell line and PDCs sensitive to triptolide but, not in those insensitive to triptolide. The Chk2 phophorylation suggested that triptolide had the anti-tumor effect through inducing the apoptosis of tumor cells. These findings suggest that triptolide might be a promising targeted therapy for pancreatic cancer patients with KRAS mutant type.

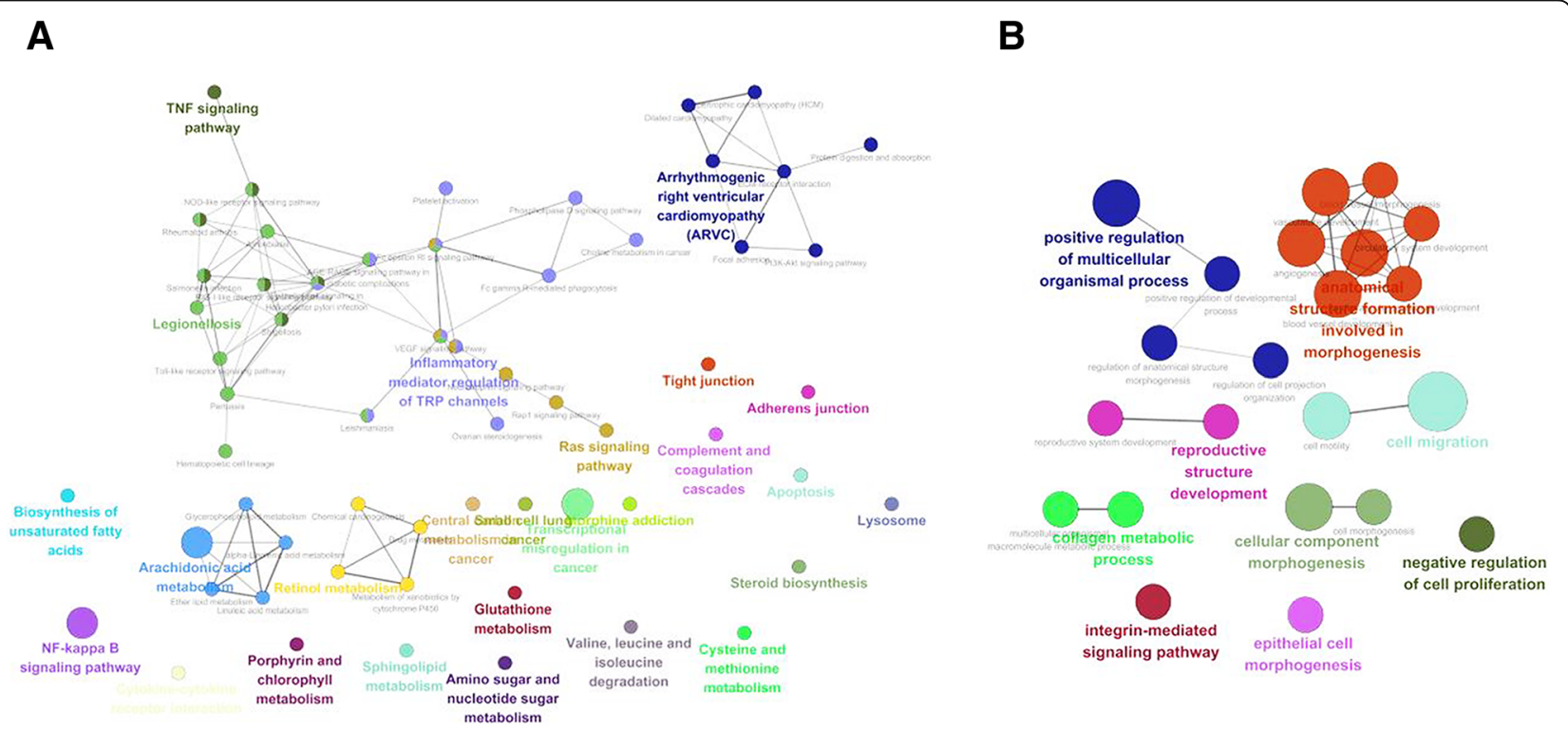

Fig. 2 ClueGO network for top correlating DEGs. The size of the nodes reflects the statistical significance of the terms. A term can be included in more than one group. Different groups were colored differently. The group leading term (in bold) is the most significant term of the group. a $A$ ClueGO network in KEGG for DEGs. b A ClueGO network in GO_BP for DEGs ( $P$-value < 0.05 ) 


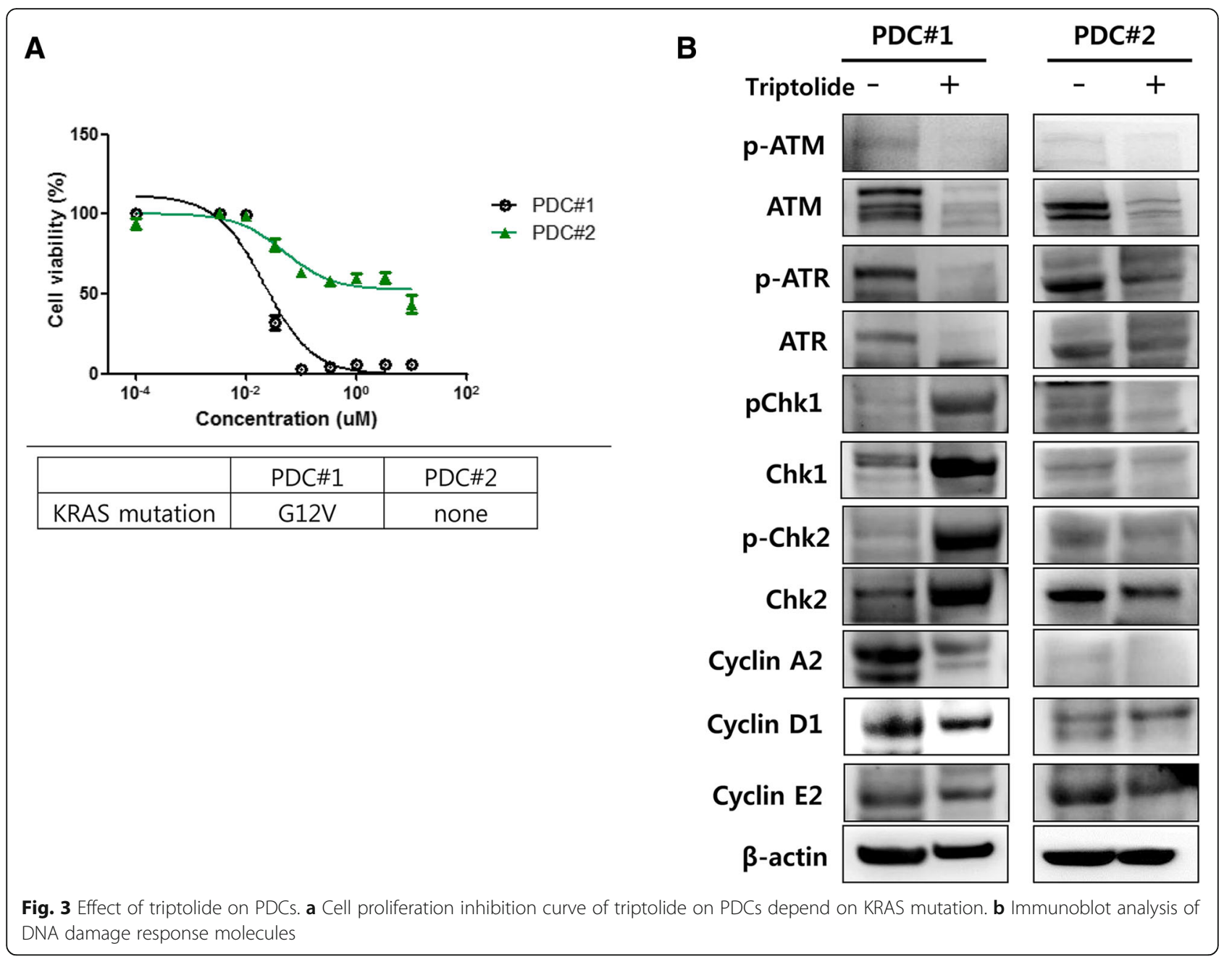

Triptolide is a diterpene triepoxide which causes cell death in pancreatic, colon and breast cancer as well as cholangiocarcinoma and neuroblastoma cells among others [13, 21, 22]. Triptolide has been demonstrated to possess potent antitumor activity and induce apoptosis in a variety of tumor types in vivo and in vitro [12-14]. Triptolide has been reported to effect multiple pathways such as HSP70, HSF1, and Bcl-2 families [13, 23, 24]. In our pathway analysis using gene expression profiling, we could find that the antitumor effect of triptolide is associated with integrin mediated pathway. Integrins has been known to regulate the apoptotic response to DNA damage [25]. In this aspect, our outcome of analysis for pathway is well matched to the theoretical mechanism of triptolide. Additionally, in the immunoblot assay, we found that Chk2 phosphorylation was distinctively observed in PDCs sensitive to triptolide but, not PDCs insensitive to triptolide. Chk2 phosphorylation suggested that the antitumor effect to triptolide was associated with the apoptotic response [26, 27].
Our data was shown that genes of RAS pathway were differentially expressed between sensitive and non-sensitive cell lines and PDC with KRAS mutation was more sensitive to triptolide than without KRAS mutation. It has been reported that anti-tumor effect of triptolide is related to integrin-mediated RAS signaling pathway and DNA damage response in cancer [28]. However, further evaluation of the dependency of KRAS mutation to apoptosis via Chk2 phosphorylation is required to elucidate the mechanism.

KRAS mutation subtypes might induce different tumor biology in the same tumor type [29-33]. In pancreatic cancer and non-small cell lung cancer (NSCLC), the mutation subtype G12D and G12 V were associated with the different PI3K/AKT and MEK casade. In ovary serous carcinoma, patients with KRAS G12 V mutation had poor survival than those with KRAS G12D mutation or KRAS wild type [34]. Although triptolide showed remarkable antitumor activity in KRAS G12 V mutant PDCs in present study, our study dealt with only one PDC with KRAS mutation. Thus, our data needs to be 


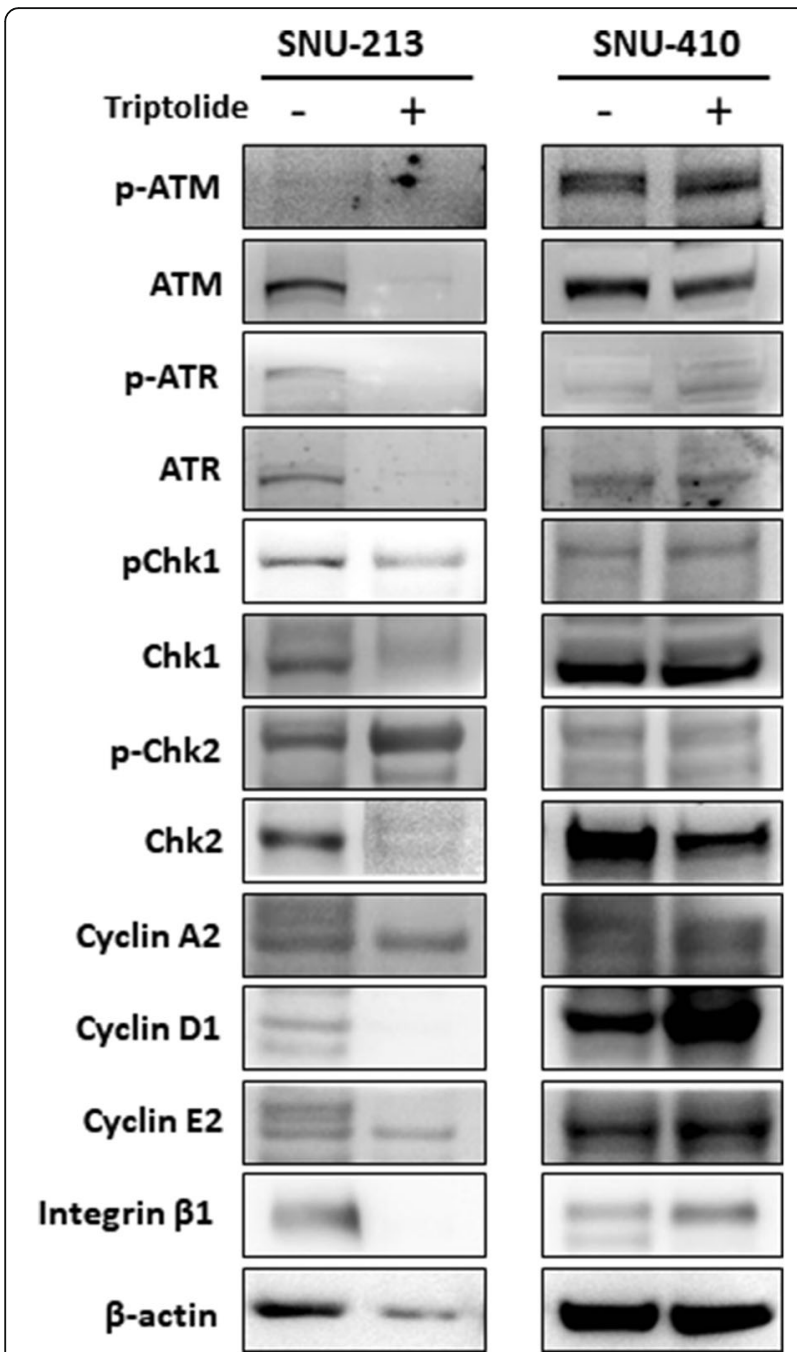

Fig. 4 Effect of triptolide on DNA damage response in pancreatic cancer cell line: Immunoblot analysis of markers in DNA damage response

interpreted with the caution. Our gene expression analysis based on pancreatic cancer cell lines also showed that different KRAS mutation subtypes had different gene expression profiling. These suggested that KRAS mutation subtypes might be robust biomarker to triptolide. Thus, which specific subtype of KRAS mutation is sensitive to triptolide needs to be resolved.

Clinical application of triptolide was limited because it was poorly soluble in water but soluble in organic solvent. To overcome problems with solubility, a highly water soluble analogue of triptolide, named minnelide has been designed and synthesized [11]. Recently, phase I clinical trial using minnelide in gastrointestinal tumor has been completed (NCT01927965). Currently, phase II clinical trial of minnelide in refractory pancreatic cancer is on going (NCT03117920). Our findings might be helpful to completely capture the subset of patients who may benefit to minnelide. More robust biomarkers and careful clinical trial design using minnelide are warranted.

\section{Conclusion}

Our findings might be helpful to completely capture the subset of patients who may benefit to tripolide (minnelide). Triptolide showed antitumor activity in KRAS G12 V mutant PDCs in present study, further elucidation of KRAS mutation dependency of apoptosis via Chk2 phosphorylation is required. More robust biomarkers and careful clinical trial design using triptolide (minnelide) are warranted.

\section{Additional file}

Additional file 1: Table S1. Top 20 genes upregulated in sensitive cell

lines to triptolide. (XLSX $10 \mathrm{~kb}$ )

Abbreviations

PC: Pancreatic cancer; PDC: Patient derived cell

\section{Acknowledgements}

Support was provided by a grant from the Korean Health Technology R\&D Project, Ministry of Health \& Welfare, Republic of Korea (HI14C2640,

HI14C3418, HI14C2750). Support was also provided by a grant from Basic Science Research Program through the National Research Foundation of Korea (NRF) funded by the Ministry of Education (2016R1A6A3A11932444, 2018R1D1A1B07048349).

\section{Funding}

"The Korean Health Technology R\&D Project, Samsung Medical Center and National Research Foundation of Korea". The funding body played neither a role in the design of the study nor in data collection, analysis, interpretation nor in writing the manuscript.

Availability of data and materials

The datasets used and/or analyzed during the current study are available from the corresponding author on reasonable request.

\section{Authors' contributions}

Conception and design were carried out by STK, JYL and JOP. Development of methodology was conducted by STK, KK, SYK, SHP and YOP. Analysis and interpretation of data were conducted by KK, STK, and SYK. Writing, review and/or revision of manuscript were carried out by STK, HYL, JL, and WKK. STK, SYK, KK, SHP, YSP, JYL, SHP, and JOP participated in administrative, technical or material support. Study supervision was conducted by JOP. All authors read and approved the final manuscript.

Ethics approval and consent to participate

Our investigation was conducted in accordance with contemporary ethical standards, the Declaration of Helsinki, and national and international guidelines. This study was approved by the authors' institutional review board (Samsung Medical Center).

\section{Consent for publication}

Not applicable.

\section{Competing interests}

The authors declare that they have no competing interests.

\section{Publisher's Note}

Springer Nature remains neutral with regard to jurisdictional claims in published maps and institutional affiliations. 
Received: 23 March 2018 Accepted: 24 October 2018

Published online: 12 November 2018

\section{References}

1. Rosenberg L. Pancreatic cancer: a review of emerging therapies. Drugs. 2000;59(5):1071-89.

2. Bilimoria KY, Bentrem DJ, Ko CY, Stewart AK, Winchester DP, Talamonti MS National failure to operate on early stage pancreatic cancer. Ann Surg. 2007; 246(2):173-80.

3. Zuckerman DS, Ryan DP. Adjuvant therapy for pancreatic cancer: a review. Cancer. 2008;112(2):243-9.

4. Wolfgang CL, Herman JM, Laheru DA, Klein AP, Erdek MA, Fishman EK, Hruban RH. Recent progress in pancreatic cancer. CA Cancer J Clin. 2013; 63(5):318-48.

5. Oettle $\mathrm{H}$. Progress in the knowledge and treatment of advanced pancreatic cancer: from benchside to bedside. Cancer Treat Rev. 2014;40(9):1039-47.

6. Storz P. Targeting the alternative NF-kappaB pathway in pancreatic cancer: a new direction for therapy? Expert Rev Anticancer Ther. 2013;13(5):501-4.

7. Ryan DP, Hong TS, Bardeesy N. Pancreatic adenocarcinoma. N Engl J Med. 2014;371(22):2140-1.

8. Moyer MT, Gaffney RR. Pancreatic adenocarcinoma. N Engl J Med. 2014; 371(22):2140.

9. Forbes SA, Bindal N, Bamford S, Cole C, Kok CY, Beare D, Jia M, Shepherd R, Leung K, Menzies A, et al. COSMIC: mining complete cancer genomes in the catalogue of somatic mutations in cancer. Nucleic Acids Res. 2011; 39(Database issue):D945-50.

10. Xu B, Guo X, Mathew S, Armesilla AL, Cassidy J, Darling JL, Wang W. Triptolide simultaneously induces reactive oxygen species, inhibits NFkappaB activity and sensitizes 5-fluorouracil in colorectal cancer cell lines. Cancer Lett. 2010;291(2):200-8.

11. Chugh R, Sangwan V, Patil SP, Dudeja V, Dawra RK, Banerjee S, Schumacher RJ, Blazar BR, Georg Gl, Vickers SM, et al. A preclinical evaluation of minnelide as a therapeutic agent against pancreatic cancer. Sci Transl Med. 2012:4(156):156ra139.

12. Huang W, He T, Chai C, Yang Y, Zheng Y, Zhou P, Qiao X, Zhang B, Liu Z, Wang J, et al. Triptolide inhibits the proliferation of prostate cancer cells and down-regulates SUMO-specific protease 1 expression. PLoS One. 2012 7(5):e37693.

13. Phillips PA, Dudeja V, McCarroll JA, Borja-Cacho D, Dawra RK, Grizzle WE, Vickers SM, Saluja AK. Triptolide induces pancreatic cancer cell death via inhibition of heat shock protein 70. Cancer Res. 2007;67(19):9407-16.

14. Shamon LA, Pezzuto JM, Graves JM, Mehta RR, Wangcharoentrakul S, Sangsuwan R, Chaichana S, Tuchinda P, Cleason P, Reutrakul V. Evaluation of the mutagenic, cytotoxic, and antitumor potential of triptolide, a highly oxygenated diterpene isolated from Tripterygium wilfordii. Cancer Lett. 1997;112(1):113-7

15. Barretina J, Caponigro G, Stransky N, Venkatesan K, Margolin AA, Kim S, Wilson CJ, Lehar J, Kryukov GV, Sonkin D, et al. The cancer cell line encyclopedia enables predictive modelling of anticancer drug sensitivity. Nature. 2012:483(7391):603-7.

16. Servant N, Gravier E, Gestraud P, Laurent C, Paccard C, Biton A, Brito I, Mandel J, Asselain B, Barillot E, et al. EMA - a R package for easy microarray data analysis. BMC Res Notes. 2010;3:277.

17. Bindea G, Mlecnik B, Hackl H, Charoentong P, Tosolini M, Kirilovsky A, Fridman WH, Pages F, Trajanoski Z, Galon J. ClueGO: a cytoscape plug-in to decipher functionally grouped gene ontology and pathway annotation networks. Bioinformatics. 2009;25(8):1091-3.

18. Shannon P, Markiel A, Ozier O, Baliga NS, Wang JT, Ramage D, Amin N, Schwikowski B, Ideker T. Cytoscape: a software environment for integrated models of biomolecular interaction networks. Genome Res. 2003;13(11): 2498-504.

19. Kim ST, Lee J, Hong M, Park K, Park JO, Ahn T, Park SH, Park YS, Lim HY, Sun $J M$, et al. The NEXT-1 (Next generation pErsonalized tX with mulTi-omics and preclinical model) trial: prospective molecular screening trial of metastatic solid cancer patients, a feasibility analysis. Oncotarget. 2015;6(32): 33358-68.

20. Le Tourneau C, Delord JP, Goncalves A, Gavoille C, Dubot C, Isambert N, Campone M, Tredan O, Massiani MA, Mauborgne C, et al. Molecularly targeted therapy based on tumour molecular profiling versus conventional therapy for advanced cancer (SHIVA): a multicentre, open-label, proof-of- concept, randomised, controlled phase 2 trial. Lancet Oncol. 2015;16(13): 1324-34.

21. Antonoff MB, Chugh R, Borja-Cacho D, Dudeja V, Clawson KA, Skube SJ, Sorenson BS, Saltzman DA, Vickers SM, Saluja AK. Triptolide therapy for neuroblastoma decreases cell viability in vitro and inhibits tumor growth in vivo. Surgery. 2009;146(2):282-90.

22. Clawson KA, Borja-Cacho D, Antonoff MB, Saluja AK, Vickers SM. Triptolide and TRAIL combination enhances apoptosis in cholangiocarcinoma. J Surg Res. 2010;163(2):244-9.

23. Dudeja V, Chugh RK, Sangwan V, Skube SJ, Mujumdar NR, Antonoff MB, Dawra RK, Vickers SM, Saluja AK. Prosurvival role of heat shock factor 1 in the pathogenesis of pancreatobiliary tumors. Am J Physiol Gastrointest Liver Physiol. 2011;300(6):G948-55.

24. Sangwan V, Banerjee S, Jensen KM, Chen Z, Chugh R, Dudeja V, Vickers SM, Saluja AK. Primary and liver metastasis-derived cell lines from KrasG12D; Trp53R172H; Pdx-1 Cre animals undergo apoptosis in response to triptolide. Pancreas. 2015;44(4):583-9.

25. Lewis JM, Truong TN, Schwartz MA. Integrins regulate the apoptotic response to DNA damage through modulation of p53. Proc Natl Acad Sci U S A. 2002;99(6):3627-32.

26. Hirao A, Kong YY, Matsuoka S, Wakeham A, Ruland J, Yoshida H, Liu D, Elledge SJ, Mak TW. DNA damage-induced activation of p53 by the checkpoint kinase Chk2. Science. 2000;287(5459):1824-7.

27. Zannini L, Delia D, Buscemi G. CHK2 kinase in the DNA damage response and beyond. J Mol Cell Biol. 2014;6(6):442-57.

28. Subramani D, Alahari SK. Integrin-mediated function of Rab GTPases in cancer progression. Mol Cancer. 2010;9:312.

29. Ihle NT, Byers LA, Kim ES, Saintigny P, Lee JJ, Blumenschein GR, Tsao A, Liu S, Larsen JE, Wang J, et al. Effect of KRAS oncogene substitutions on protein behavior: implications for signaling and clinical outcome. J Natl Cancer Inst. 2012;104(3):228-39.

30. Cserepes M, Ostoros G, Lohinai Z, Raso E, Barbai T, Timar J, Rozsas A, Moldvay J, Kovalszky I, Fabian K, et al. Subtype-specific KRAS mutations in advanced lung adenocarcinoma: a retrospective study of patients treated with platinum-based chemotherapy. Eur J Cancer. 2014;50(10):1819-28.

31. Guibert N, Ilie M, Long E, Hofman V, Bouhlel L, Brest P, Mograbi B, Marquette $\mathrm{CH}$, Didier A, Mazieres J, et al. KRAS mutations in lung adenocarcinoma: molecular and epidemiological characteristics, methods for detection, and therapeutic strategy perspectives. Curr Mol Med. 2015; 15(5):418-32.

32. Neuzillet C, Hammel P, Tijeras-Raballand A, Couvelard A, Raymond E. Targeting the Ras-ERK pathway in pancreatic adenocarcinoma. Cancer Metastasis Rev. 2013;32(1-2):147-62.

33. Sun $C$, Rosendahl $A H$, Andersson $R$, Wu D, Wang $X$. The role of phosphatidylinositol 3-kinase signaling pathways in pancreatic cancer. Pancreatology. 2011;11(2):252-60.

34. Tsang YT, Deavers MT, Sun CC, Kwan SY, Kuo E, Malpica A, Mok SC, Gershenson DM, Wong KK. KRAS (but not BRAF) mutations in ovarian serous borderline tumour are associated with recurrent low-grade serous carcinoma. J Pathol. 2013:231(4):449-56.

Ready to submit your research? Choose BMC and benefit from

- fast, convenient online submission

- thorough peer review by experienced researchers in your field

- rapid publication on acceptance

- support for research data, including large and complex data types

- gold Open Access which fosters wider collaboration and increased citations

- maximum visibility for your research: over $100 \mathrm{M}$ website views per year

At $\mathrm{BMC}$, research is always in progress.

Learn more biomedcentral.com/submission 